\title{
Could remnant-like particle cholesterol become a risk factor in diabetic menopausal women with coronary artery disease? A cross-sectional study of single academic center in China
}

\author{
Xunxun Feng ${ }^{\dagger}$, Qianyun Guo ${ }^{\dagger}$, Shu Zhou, Tienan Sun, Yuyang Liu, Zhiming Zhou and Yujie Zhou*
}

\begin{abstract}
Background and aims: It has been confirmed that remnant-like particle cholesterol (RLP-C) mediates the progression of coronary artery disease (CAD). Currently there is limited information on RLP-C in menopausal women. With the special status of diabetes mellitus (DM) combined with the special body changes of the menopausal women, the RLP-C is particularly important when studying the changes that occurred in response to CAD and its associated risk factors. This study discussed whether RLP-C could be an independent risk factor for menopausal women with CAD and DM.
\end{abstract}

Methods: The cohort consisted of 4753 menopausal women who had undergone coronary angiography. Subjects were separated into CAD and non-CAD groups, and univariate and multivariate logistic regression analysis of CAD risk factors were performed. All patients with a history of DM were divided into DM subgroups. Then, the univariate and multivariate logistic regression analysis of the risk factors of CAD and the comparison among age groups in the DM subgroup were performed. After age stratification of the DM group, the Kruskal-Wallis test was used to analyze the differences of various lipid indexes among age groups.

Results: The multivariate logistic regression showed that RLP-C was an independent risk factor for CAD in menopausal women (OR 1.232, 95\% Cl 1.070-1.419). In the DM subgroup, it was also found that RLP-C was an independent risk factor for CAD (OR 1.366, 95\%Cl 1.043-1.791). Kruskal-Wallis test analysis found that RLP-C had no significant difference among three groups $(P>0.05)$.

Conclusions: RLP-C was proved to be an independent risk factor for menopausal women with CAD and DM. Keywords: Remnant-like particle cholesterol, Coronary artery disease, Menopausal women, Diabetes mellitus

\footnotetext{
*Correspondence: azzyj12@163.com

${ }^{\dagger}$ Xunxun Feng and Qianyun Guo were contributed equally to the article as the first authors.

Department of Cardiology, Beijing Anzhen Hospital, Capital Medical University, Beijing Institute of Heart Lung and Blood Vessel Disease, Beijing Key Laboratory of Precision Medicine of Coronary Atherosclerotic Disease, Clinical center for coronary heart disease, Capital Medical University, Beijing 100029, China
}

C C The Author(s). 2020 Open Access This article is licensed under a Creative Commons Attribution 4.0 International License, which permits use, sharing, adaptation, distribution and reproduction in any medium or format, as long as you give appropriate credit to the original author(s) and the source, provide a link to the Creative Commons licence, and indicate if changes were made. The images or other third party material in this article are included in the article's Creative Commons licence, unless indicated otherwise in a credit line to the material. If material is not included in the article's Creative Commons licence and your intended use is not permitted by statutory regulation or exceeds the permitted use, you will need to obtain permission directly from the copyright holder. To view a copy of this licence, visit http://creativecommons.org/licenses/by/4.0/. The Creative Commons Public Domain Dedication waiver (http://creativecommons.org/publicdomain/zero/1.0/) applies to the data made available in this article, unless otherwise stated in a credit line to the data. 


\section{Background}

The high rates of morbidity and mortality of CAD are related to high levels of RLP-C [1]. Currently, the clinical lipid-lowering treatment of CAD patient's targets lowdensity lipoprotein cholesterol (LDL-C), but among the many indexes of blood lipid, other potential targets remain. For CAD patients with decreased LDL-C, it is found that RLP-C may be an important target for the treatment of blood lipids in CAD patients after treatment of LDL-C [2]. RLP-C levels could also be used to predict the onset of $\mathrm{CAD}$ in different populations, thus confirming that RLP-C measurement is beneficial for risk assessment and treatment assessment of CAD patients [3]. Although RLP$\mathrm{C}$ is a risk factor for cardiovascular related atherosclerotic disease, there is currently no standard method of measurement and the research potential of RLP-C is huge [4]. It has been found that an increase of $1 \mathrm{mmol} / \mathrm{L}$ in nonfasting RLP-C could increase the risk of ischemic heart disease by 2.8 times [5]. Studies have also confirmed that RLP-C affected the formation of atherosclerosis by affecting a variety of cells [6]. In addition, the RLP-C associates with atherosclerosis through blood lipid levels, insulin resistance, and it is frequently of abnormally high levels in diabetic patients [7]. While the importance of RLP-C on in-stent restenosis in DM patients has been confirmed, very few studies have been carried out in menopausal women with DM $[8,9]$. Therefore, our aim was to determine whether RLP-C could be an independent risk factor in menopausal women with DM and CAD.

\section{Methods}

\section{Study patients}

Our study included 4753 menopausal women over the age of 50 who had undergone coronary angiography from January 2015 to December 2015. Subjects were designated into CAD $(n=2874)$ and non-CAD groups $(n=1897)$ according to coronary angiography assessments. Those with a history of DM were screened from the study population and divided into the DM subgroups, including DM combined with CAD group $(n=1031)$ and DM combined with non-CAD group $(n=465)$.

\section{Data collection}

Demographic and clinical characteristics of patients were collected using standard case report forms, including age; body mass index (BMI); blood pressure including systolic blood pressure (SBP) and diastolic blood pressure (DBP); history of smoking, history of drinking; medical history including DM, hypertension (HT), hyperlipidemia, family history of cardiovascular disease (CVD); and medication therapy.

\section{Laboratory analysis}

Fasting blood samples were obtained from study participants at the baseline. Total cholesterol (TC) and triglyceride (TG) levels were assessed in enzymatic assays. The levels of LDL-C and high-density lipoprotein cholesterol (HDL-C) were determined using homogeneous methods [10]. RLP-C calculation was defined as TC- (LDL-C + HDL-C) $[11,12]$.

\section{Statistics}

Data were compared via the SPSS 22.0 statistical software package. Data were the mean \pm SD for continuous variables, and ration for classified variables. Group differences were calculated in two-sided t-tests. Chi-square tests were used to represent classified variables which were shown as counts (percentage). Univariate analysis was carried out, and then these variables were selected and added to the multivariate analysis. Continuous variables across the age groups were compared using Kruskal-Wallis assessments. $P<0.05$ (bilateral) was considered statistically significant.

\section{Results \\ Baseline data}

In the overall population, there were 1496 DM patients (1496/4753, 31.47\%), accounting for more than $1 / 3$ of the total population, which differed between the CAD and non-CAD groups (465 [24.75\%] vs 1031 [35.87\%]; $P<0.001)$. HT $(3198 / 4753,67.28 \% ; 1191$ [63.38\%] vs 2007 [69.83\%]; $P<0.001)$ and hyperlipidemia (1867/ 4753, 39.28\%; 748 [39.81\%] vs 1119 [38.94\%]; $P=0.547)$ accounted for a very large proportion of the population and $\mathrm{HT}$ differed between $\mathrm{CAD}$ and non-CAD groups. This might be related to the high proportion of HT population in China and the characteristics of blood lipids in menopausal women. In terms of laboratory results of blood lipid, TG $(1.63 \pm 1.07$ vs $1.75 \pm 1.18$; $P<$ $0.001), H D L-C(1.18 \pm 0.30$ vs $1.10 \pm 0.26 ; P<0.001)$, and RLP-C $(0.68 \pm 0.43$ vs $0.72 \pm 0.47 ; P=0.001)$ differed between the CAD and non-CAD groups (Table 1). In the laboratory results of the DM subgroup, TG $(1.76 \pm 1.03$ vs $1.91 \pm 1.45 ; P=0.048)$, HDL-C $(1.12 \pm 0.29$ vs $1.06 \pm$ $0.25 ; P=0.001)$, and RLP-C $(0.70 \pm 0.42$ vs $0.76 \pm 0.51$; $P=0.024$ ) differed across the CAD and non-CAD groups. No changes in LDL-C levels in either the general population or the DM subgroup $(P>0.05)$. (Table 2$)$.

\section{CAD risk factor assessment through univariate model assessments}

In the overall population, univariate analysis showed that age (OR 1.028, 95\%CI 1.020-1.036, $P<0.001$ ), BMI (OR 1.027, 95\%CI 1.009-1.046, $P=0.003$ ), SBP (OR 1.010, 95\%CI 1.006-1.014, $P<0.001$ ), DBP (OR 1.015, 95\%CI $1.009-1.020, P<0.001$ ), family history of CVD (OR 0.709, 95\%CI 0.547-0.919, $P=0.009$ ), HDL-C (OR 0.373, 95\%CI $0.301-0.462, P<0.001$ ), HT (OR 1.337, 95\%CI 1.182-1.512, $P<0.001$ ), DM (OR 1.701, 95\%CI 1.494- 
Table 1 Baseline of study population

\begin{tabular}{|c|c|c|c|c|}
\hline & $\begin{array}{l}\text { Total } \\
(n=4753)\end{array}$ & $\begin{array}{l}\text { non-CAD } \\
(n=1879)\end{array}$ & $\begin{array}{l}\text { CAD } \\
(n=2874)\end{array}$ & $P$ value \\
\hline Age, years & $64.18 \pm 7.42$ & $63.27 \pm 7.38$ & $64.77 \pm 7.39$ & $<0.001$ \\
\hline $\mathrm{BMl}, \mathrm{kg} / \mathrm{m}^{2}$ & $25.15 \pm 3.29$ & $24.98 \pm 3.07$ & $25.27 \pm 3.43$ & $<0.001$ \\
\hline $\mathrm{SBP}, \mathrm{mmHg}$ & $129.08 \pm 15.70$ & $127.63 \pm 15.74$ & $130.03 \pm 15.60$ & $<0.001$ \\
\hline $\mathrm{DBP}, \mathrm{mmHg}$ & $74.98 \pm 11.83$ & $73.88 \pm 11.26$ & $75.70 \pm 12.14$ & $<0.001$ \\
\hline Smoking, n(\%) & $309(6.50)$ & $102(5.43)$ & $207(7.20)$ & 0.015 \\
\hline Drinking, n(\%) & $14(0.29)$ & $6(0.32)$ & $8(0.28)$ & 0.799 \\
\hline \multicolumn{5}{|l|}{ Medical history, n(\%) } \\
\hline $\mathrm{DM}, \mathrm{n}(\%)$ & $1496(31.47)$ & $465(24.75)$ & $1031(35.87)$ & $<0.001$ \\
\hline HT, n (\%) & $3198(67.28)$ & $1191(63.38)$ & $2007(69.83)$ & $<0.001$ \\
\hline Hyperlipidemia, n(\%) & $1867(39.28)$ & $748(39.81)$ & $1119(38.94)$ & 0.547 \\
\hline Family history of CVD, $\mathrm{n}(\%)$ & $242(5.09)$ & $115(6.12)$ & $127(4.42)$ & 0.009 \\
\hline \multicolumn{5}{|l|}{ Laboratory results } \\
\hline $\mathrm{TC}, \mathrm{mmol} / \mathrm{L}$ & $4.46 \pm 1.08$ & $4.48 \pm 1.04$ & $4.45 \pm 1.11$ & 0.348 \\
\hline $\mathrm{TG}, \mathrm{mmol} / \mathrm{L}$ & $1.70 \pm 1.14$ & $1.63 \pm 1.07$ & $1.75 \pm 1.18$ & $<0.001$ \\
\hline $\mathrm{LDL}-\mathrm{C}, \mathrm{mmol} / \mathrm{L}$ & $2.63 \pm 0.90$ & $2.63 \pm 0.86$ & $2.62 \pm 0.92$ & 0.957 \\
\hline $\mathrm{HDL}-\mathrm{C}, \mathrm{mmol} / \mathrm{L}$ & $1.13 \pm 0.28$ & $1.18 \pm 0.30$ & $1.10 \pm 0.26$ & $<0.001$ \\
\hline non-HDL-C, mmol/L & $3.33 \pm 1.04$ & $3.30 \pm 0.99$ & $3.35 \pm 1.07$ & 0.141 \\
\hline $\mathrm{RLP}-\mathrm{C}, \mathrm{mmol} / \mathrm{L}$ & $0.71 \pm 0.45$ & $0.68 \pm 0.43$ & $0.72 \pm 0.47$ & 0.001 \\
\hline \multicolumn{5}{|l|}{ Medical treatment, n(\%) } \\
\hline Aspirin & $4109(86.45)$ & $1541(82.01)$ & $2568(89.35)$ & $<0.001$ \\
\hline Clopidogrel & $2933(61.71)$ & $812(43.21)$ & $2121(73.80)$ & $<0.001$ \\
\hline Statins & $3476(73.13)$ & $1360(72.38)$ & $2116(73.63)$ & 0.343 \\
\hline$\beta$-blockers & $2941(61.88)$ & $1092(58.12)$ & $1849(64.34)$ & $<0.001$ \\
\hline ARB & $1005(21.14)$ & $369(19.64)$ & $636(22.13)$ & 0.040 \\
\hline ACEI & $242(5.09)$ & 74 (3.94) & $168(5.85)$ & 0.003 \\
\hline
\end{tabular}

$B M I$ body mass index, SBP systolic blood pressure, DBP diastolic blood pressure, $D M$ diabetes mellitus, $H T$ hypertension, $C V D$ cardiovascular disease, $C A D$ coronary artery disease, $T C$ total cholesterol, $T G$ triglyceride, $L D L-C$ low-density lipoprotein cholesterol, $H D L-C$ high-density lipoprotein cholesterol, $R L P$ - $C$ remnant-like particle cholesterol, $A C E I$ angiotensin converting enzyme inhibitor, $A R B$ angiotensin receptor blocker

1.936, $P<0.001$ ), TG (OR 1.104, 95\%CI 1.044-1.166, $P<0.001$ ), RLP-C (OR 1.274, 95\%CI 1.107-1.467, $P=$ 0.001 ) were risks of CAD with obvious and positive effects, while statin therapy, drinking history, hyperlipidemia, TC, LDL-C, and non-HDL-C were not significant risk factors for $\mathrm{CAD}(P>0.05)$. In the $\mathrm{DM}$ subgroup population, HDL-C (OR 0.478, 95\%CI 0.317-0.719, $P<$ 0.001 ) and RLP-C (OR 1.354, 95\%CI 1.037-1.767, $P=$ 0.026) were significant risks for CAD. (Fig. 1).

\section{CAD risk factors through multivariate logistic regression} In the overall population, after adjusting for age, BMI, smoking history, statin therapy, DM, HT, and LDL-C and RLP-C, regression analysis in overall population revealed RLP-C would be a strong CAD risk (OR 1.232, 95\%CI $1.070-1.419, P=0.004)$. It was also noted that RLP-C could be a significant risk of CAD in the DM population (OR 1.366, 95\%CI 1.043-1.791, $P=0.024$ ). (Fig. 2).

\section{Kruskal-Wallis test analysis}

The DM subgroup was grouped according to age and divided into three groups: women aged 50-59, 60-69, or $\geq$ 70 years old. It was found that in different populations, blood lipid indicators included LDL-C, TG, TC, non -HDL-C differed across the groups of those $\geq 70$ years old, which were higher than the other assessed groups (LDL-C, $P=0.001 ;$ TG, $P=0.003$; TC, $P<0.001$; nonHDL-C, $P<0.001)$, while RLP-C $(P=0.191)$ and HDL-C $(P=0.524)$ showed no changes across the three groups. (Tables 3,4).

\section{Discussion}

\section{Main findings}

We found that in the overall population of menopausal women, the RLP-C differed in CAD compared to nonCAD groups $(0.68 \pm 0.43$ vs $0.72 \pm 0.47, P=0.001)$. When the DM subgroup population was further investigated, 
Table 2 Baseline of DM population

\begin{tabular}{|c|c|c|c|c|}
\hline & $\begin{array}{l}\text { DM Total } \\
(n=1496)\end{array}$ & $\begin{array}{l}\text { non-CAD } \\
(n=465) \\
\end{array}$ & $\begin{array}{l}\text { CAD } \\
(n=1031)\end{array}$ & $P$ value \\
\hline Age, years & $65.02 \pm 7.17$ & $64.70 \pm 7.35$ & $65.16 \pm 7.09$ & 0.252 \\
\hline $\mathrm{BMl}, \mathrm{kg} / \mathrm{m}^{2}$ & $25.34 \pm 3.39$ & $25.24 \pm 3.10$ & $25.39 \pm 3.52$ & 0.433 \\
\hline $\mathrm{SBP}, \mathrm{mmHg}$ & $129.16 \pm 15.47$ & $127.35 \pm 14.81$ & $129.97 \pm 15.70$ & 0.002 \\
\hline $\mathrm{DBP}, \mathrm{mmHg}$ & $75.19 \pm 11.44$ & $73.95 \pm 11.36$ & $75.74 \pm 11.43$ & 0.005 \\
\hline Smoking, n(\%) & $85(5.68)$ & $21(4.52)$ & $64(6.21)$ & 0.191 \\
\hline Drinking, n(\%) & $2(0.13)$ & $0(0.00)$ & $2(0.19)$ & 0.342 \\
\hline \multicolumn{5}{|l|}{ Medical history, n(\%) } \\
\hline HT, n (\%) & $1176(78.61)$ & $363(78.06)$ & $813(78.86)$ & 0.730 \\
\hline Hyperlipidemia, n(\%) & $606(40.51)$ & $190(40.86)$ & $416(40.35)$ & 0.852 \\
\hline Family history of CVD, $\mathrm{n}(\%)$ & $70(4.68)$ & $23(4.95)$ & $47(4.56)$ & 0.743 \\
\hline \multicolumn{5}{|l|}{ Laboratory results } \\
\hline $\mathrm{TC}, \mathrm{mmol} / \mathrm{L}$ & $4.36 \pm 1.09$ & $4.34 \pm 1.05$ & $4.37 \pm 1.11$ & 0.708 \\
\hline $\mathrm{TG}, \mathrm{mmol} / \mathrm{L}$ & $1.86 \pm 1.34$ & $1.76 \pm 1.03$ & $1.91 \pm 1.45$ & 0.048 \\
\hline $\mathrm{LDL}-\mathrm{C}, \mathrm{mmol} / \mathrm{L}$ & $2.54 \pm 0.87$ & $2.53 \pm 0.84$ & $2.54 \pm 0.89$ & 0.761 \\
\hline $\mathrm{HDL}-\mathrm{C}, \mathrm{mmol} / \mathrm{L}$ & $1.08 \pm 0.26$ & $1.12 \pm 0.29$ & $1.06 \pm 0.25$ & 0.001 \\
\hline non-HDL-C, mmol/L & $3.28 \pm 1.04$ & $3.23 \pm 1.02$ & $3.31 \pm 1.05$ & 0.195 \\
\hline $\mathrm{RLP}-\mathrm{C}, \mathrm{mmol} / \mathrm{L}$ & $0.74 \pm 0.48$ & $0.70 \pm 0.42$ & $0.76 \pm 0.51$ & 0.024 \\
\hline \multicolumn{5}{|l|}{ Medical treatment, n(\%) } \\
\hline Insulin & $202(13.50)$ & $54(11.61)$ & $148(14.35)$ & 0.151 \\
\hline Aspirin & $1315(87.90)$ & $390(83.87)$ & 925 (89.72) & 0.001 \\
\hline Clopidogrel & $981(65.57)$ & $212(45.60)$ & 769 (74.59) & $<0.001$ \\
\hline Statins & $1113(74.40)$ & 344 (73.98) & 769 (74.59) & 0.803 \\
\hline$\beta$-blockers & $938(62.70)$ & $289(62.15)$ & 649 (62.95) & 0.768 \\
\hline ARB & $306(20.45)$ & $97(20.86)$ & $209(20.27)$ & 0.794 \\
\hline ACEI & $73(4.88)$ & $18(3.87)$ & 55 (5.33) & 0.224 \\
\hline
\end{tabular}

$B M I$ body mass index, SBP systolic blood pressure, DBP diastolic blood pressure, $H T$ hypertension, $C V D$ cardiovascular disease, CAD coronary artery disease, $T C$ total cholesterol, TG triglyceride, $L D L-C$ low-density lipoprotein cholesterol, HDL-C high-density lipoprotein cholesterol, $R L P$-C remnant-like particle cholesterol, ACEI angiotensin converting enzyme inhibitor, $A R B$ angiotensin receptor blocker

the RLP-C differed between CAD and non-CAD menopausal women $(0.70 \pm 0.42$ vs $0.76 \pm 0.51, P=0.024)$. The RLP-C showed no change according to age in diabetic women (TC, $\mathrm{P}=0.001$; TG, $P=0.003$; LDL-C, $P<0.001$; HDL-C, $P=0.524$; RLP-C, $P=0.191$ ), confirming that along with the age growing, RLP-C might be more stable than other kinds of lipids among the menopausal women with CAD and DM.

\section{Inspiration from basic and clinical studies of dyslipidemia in menopausal women with DM and CAD}

\section{LDL-C and TG}

The blood lipid in DM patients was characterized by the decreased HDL-C levels, the increased TG-rich lipoprotein levels, and abnormal composition of high-density lipoprotein (HDL), low-density lipoprotein (LDL), and TG-rich lipoprotein particles [13]. The 2019 European
Society of Cardiology guidelines recommended that for the high-risk type $2 \mathrm{DM}$ patients, the LDL-C levels should be reduced to more than $50 \%$ of the baseline levels, and target levels of LDL-C were $\leq 1.8 \mathrm{mmol} / \mathrm{L}$ [14]. However, LDL-C in the overall population and subgroups of female patients failed to reach the ascribed standards. It was also seen that the LDL-C levels noted in this study were not consistent with common CAD and non-CAD populations, which was generally around $2.6 \mathrm{mmol} / \mathrm{L}$ (overall $2.63 \pm 0.86$ vs $2.62 \pm 0.92, P=0.957$; subgroup $2.53 \pm 0.84$ vs $2.54 \pm 0.89, \quad P=0.761)$. In addition, even at low concentrations of LDL-C controlled by statins, RLP-C could still be used as a risk factor for CAD [15]. In our study population, we found that the predictive effect of LDL-C on CAD might be less than RLP-C. In addition, studies had shown that the risk of patients with CAD and DM was related to TG metabolic disorders [16]. Previous studies had found that 

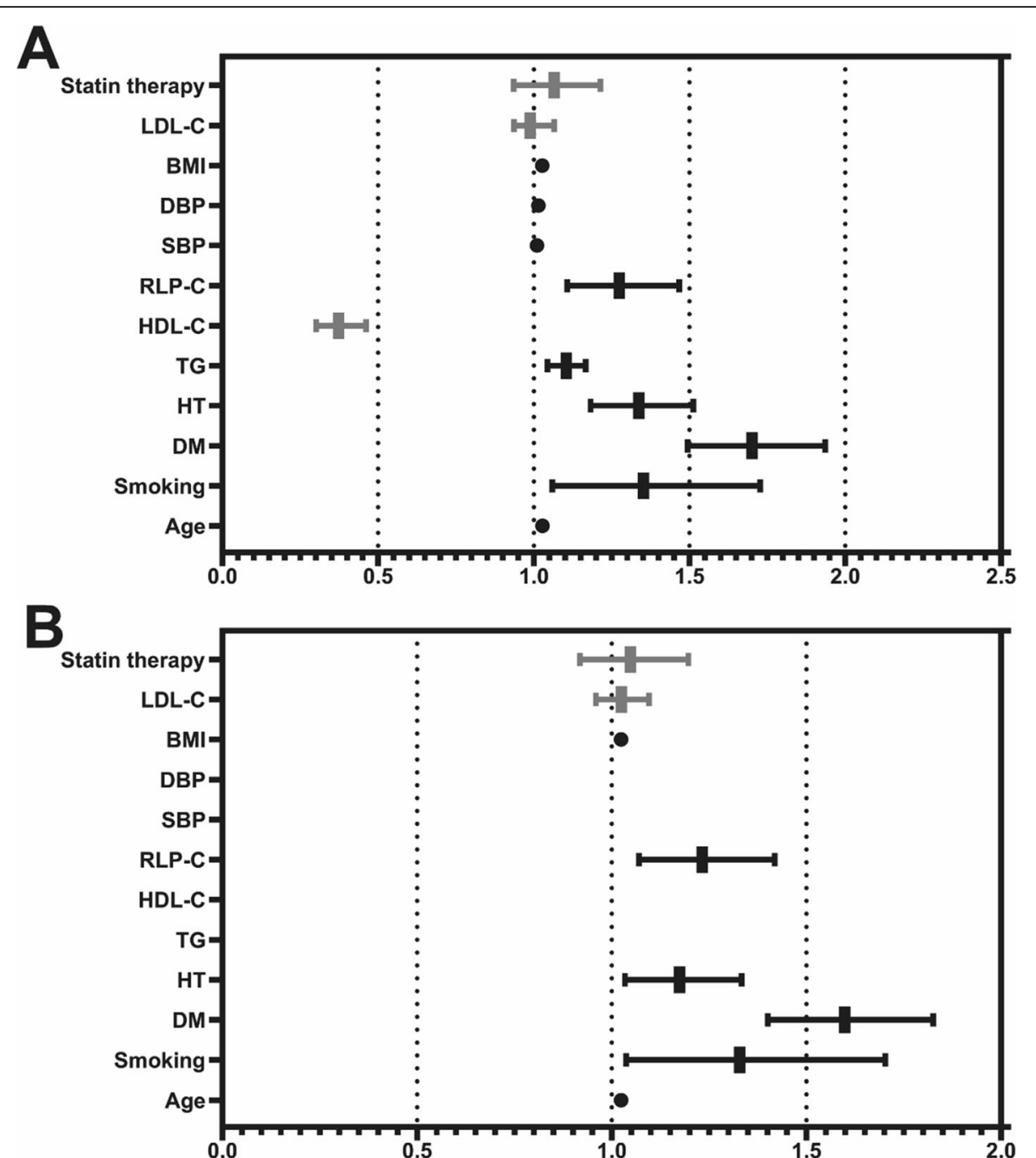

Fig. 1 Univariate and multivariate logistic regression analysis of total study population. a: the univariate logistic regression analysis in total study population (Statin therapy: OR 1.065, 95\%Cl 0.935-1.214, $P=0.343$; LDL-C: OR 0.988, 95\%Cl 0.924-1.029, $P=0.355$; BMl: OR 1.027, 95\%Cl 1.0091.046, $P=0.003$; DBP: OR 1.015, 95\%Cl 1.009-1.020, $P<0.001$; SBP: OR 1.010, 95\%Cl 1.006-1.014, $P<0.001$; RLP-C: OR 1.274, 95\%Cl 1.107-1.467, $P=$ 0.001; HDL-C: OR 0.373, 95\%Cl 0.301-0.462, P<0.001; TG: OR 1.104, 95\%Cl 1.044-1.166, $P<0.001$; HT: OR 1.337, 95\%Cl 1.182-1.512, P<0.001; DM: OR 1.701, 95\%Cl 1.494-1.936, $P<0.001$; Smoking: OR 1.352, 95\%Cl 1.059-1.727, $P=0.016$; Age: OR 1.028, 95\%Cl 1.020-1.036, $P<0.001)$. b: the multivariate logistic regression analysis with model of Statin therapy, LDL-C, BMI, RLP-C, HT, DM, Smoking and Age (Statin therapy: OR 1.048, 95\%Cl 0.918-1.197, $P=0.488 ;$ LDL-C: OR 1.025, 95\%Cl 0.959-1.096, $P=0.462 ; \mathrm{BMI}:$ OR 1.024, 95\%Cl 1.006-1.042, $P=0.011 ; \mathrm{RLP}-\mathrm{C}: \mathrm{OR} 1.232,95 \% \mathrm{Cl}$ 1.070-1.419, $P=0.004$; HT: OR 1.174, 95\%Cl 1.034-1.334, $P=0.014$; DM: OR 1.599, 95\%Cl 1.401-1.826, $P<0.001$; Smoking: OR 1.329, 95\%Cl 1.0371.703, $P=0.025$; Age: OR 1.024, 95\%Cl 1.016-1.032, P<0.001). LDL-C low-density lipoprotein cholesterol, BMI body mass index, DBP diastolic blood pressure, SBP systolic blood pressure, RLP-C remnant-like particle cholesterol, HDL-C high-density lipoprotein cholesterol, TG triglyceride, HT hypertension, DM diabetes mellitus

while elevated TG levels in DM patients did not represent an independent marker of cardiovascular events, high serum TG was associated with CVD [17]. We also found that in menopausal women, the TG levels of the overall population and DM subgroup population in the CAD group significantly differed to the non-CAD group (overall group [1.63 \pm 1.07 vs $1.75 \pm 1.18], P<0.0001$; subgroup [1.76 \pm 1.03 vs $1.91 \pm 1.45], P=0.048)$. RLP-C was a known risk factor for CVD in women and provides more information than TG [18]. Furthermore, TG and
HDL-rich lipoproteins subgroups, such as remnant-like particle (RLP), could better predict the occurrence of CAD than TG and HDL [19].

\section{RLP-C}

Studies had found that an increase of $1 \mathrm{mmol} / \mathrm{L}$ in nonfasting RLP-C could increase the risk of ischemic heart disease by 2.8 times, but was not related to the decrease of HDL-C [5]. Compared to HDL-C, LDL-C and other lipids, RLP-C, which was mainly composed of very-low-density 

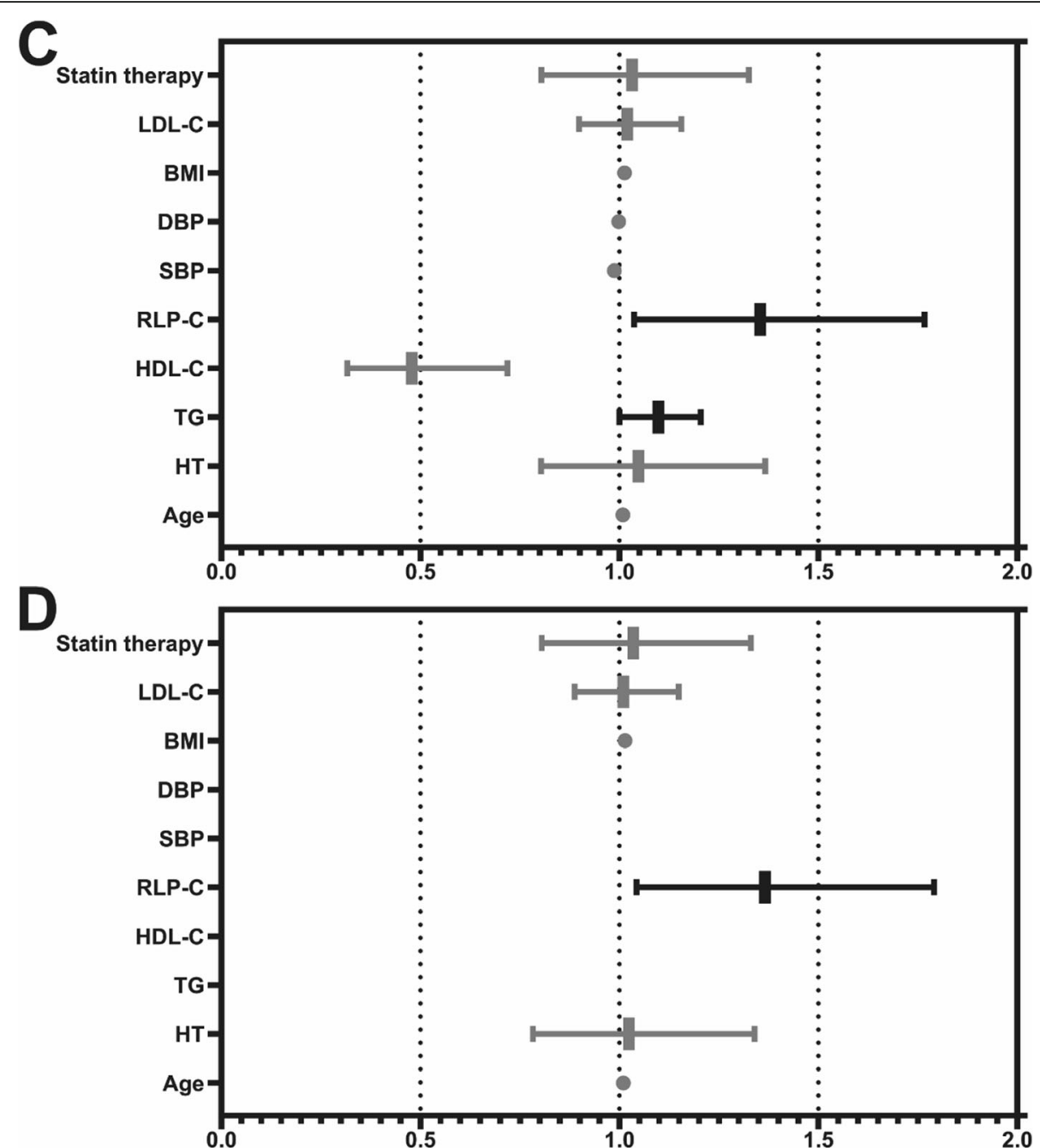

Fig. 2 Univariate and multivariate logistic regression analysis of DM population. C: the univariate logistic regression analysis in DM population (Statin therapy: OR 1.032, 95\%Cl 0.804-1.326, $P=0.803$; LDL-C: OR 1.020,95\%Cl 0.899-1.156, $P=0.761 ; \mathrm{BMI}$ : OR 1.013, 95\%Cl 0.981-1.046, $P=0.433$; DBP: OR 0.998, 95\%Cl 0.990-1.007, $P=0.704$; SBP: OR 0.988, 95\%Cl 0.981-0.994, $P<0.001$; RLP-C: OR 1.354, 95\%Cl 1.037-1.767, $P=0.026$; HDL-C: OR $0.478,95 \% \mathrm{Cl} 0.317-0.719, P<0.001$; TG: OR 1.098, 95\%Cl 1.000-1.205, $P=0.050$; HT: OR 1.048, 95\%Cl 0.803-1.367, $P=0.730 ;$ Age: OR 1.009, 95\%Cl 0.994-1.025, $P=0.252$ ). D: the multivariate logistic regression analysis with model of Statin therapy, LDL-C, BMI, RLP-C, HT and Age (Statin therapy: OR 1.035, 95\%Cl 0.805-1.331, $P=0.789$; LDL-C: OR 1.010, 95\%Cl 0.888-1.149, $P=0.879 ; \mathrm{BMI}:$ OR 1.014, 95\%Cl 0.982-1.048, $P=0.391$; RLP-C: OR 1.366, 95\%Cl 1.043-1.791, $P=0.024$; HT: OR 1.024, 95\%Cl 0.783-1.340, $P=0.863$; Age: OR 1.010, 95\%Cl 0.994-1.026, $P=0.214)$. LDL-C low-density lipoprotein cholesterol, BMI body mass index, DBP diastolic blood pressure, SBP systolic blood pressure, RLP-C remnant-like particle cholesterol, HDL-C high-density lipoprotein cholesterol, TG triglyceride, HT hypertension

lipoprotein cholesterol (VLDL-C) and intermediatedensity lipoprotein cholesterol (IDL-C), was not a common clinical lipid measurement indicator. Through direct measurement, it had been found that $1 / 3$ of total cholesterol in plasma exists in RLP-C, that was in the TG-rich intermediate-density lipoprotein (IDL) and very-lowdensity lipoprotein (VLDL) [20]. Based on the fact that RLP-C was independent of LDL-C and was related to some extent with the body's inflammatory reaction [21, 22], and the increase of RLP-C was related to low degree inflammation, combined with many studies, it was pointed out that RLP-C had an important relationship with CAD
[23]. At the same time, studies found that the menopausal women with CAD were more likely to develop DM than those without CAD. It was seen that RLP-C levels in women with DM were higher than that of women without DM [24]. Interestingly, triglyceride-rich lipoproteins (VLDL+IDL) might be associated with carotid atherosclerosis among menopausal women [25]. Therefore, increased RLP-C was an important risk factor for CAD that can predict future coronary events in DM and CAD patients [26]. We found that the RLP-C level was significantly higher in the menopausal women with CAD and the DM subgroup than that in the non-CAD group (overall group [0.68 \pm 
Table 3 Age stratification of DM population

\begin{tabular}{|c|c|c|c|c|}
\hline & $\begin{array}{l}\text { Total } \\
(n=1496)\end{array}$ & $\begin{array}{l}\text { non-CAD } \\
(n=465)\end{array}$ & $\begin{array}{l}\text { CAD } \\
(n=1031)\end{array}$ & $P$ value \\
\hline \multicolumn{5}{|c|}{$\mathrm{TC}, \mathrm{mmol} / \mathrm{L}$} \\
\hline $50-59$ & $4.43 \pm 1.12$ & $4.44 \pm 1.14$ & $4.43 \pm 1.11$ & 0.935 \\
\hline $60-69$ & $4.41 \pm 1.11$ & $4.42 \pm 1.06$ & $4.41 \pm 1.11$ & 0.918 \\
\hline$\geq 70$ & $4.16 \pm 0.98$ & $4.06 \pm 0.86$ & $4.21 \pm 1.03$ & 0.178 \\
\hline \multicolumn{5}{|c|}{$\mathrm{TG}, \mathrm{mmol} / \mathrm{L}$} \\
\hline $50-59$ & $1.97 \pm 1.49$ & $1.77 \pm 1.01$ & $2.08 \pm 1.69$ & 0.032 \\
\hline $60-69$ & $1.87 \pm 1.26$ & $1.83 \pm 1.06$ & $1.88 \pm 1.34$ & 0.649 \\
\hline$\geq 70$ & $1.74 \pm 1.33$ & $1.58 \pm 0.96$ & $1.81 \pm 1.46$ & 0.085 \\
\hline \multicolumn{5}{|c|}{$\mathrm{LDL}-\mathrm{C}, \mathrm{mmol} / \mathrm{L}$} \\
\hline $50-59$ & $2.59 \pm 0.87$ & $2.60 \pm 0.87$ & $2.58 \pm 0.87$ & 0.909 \\
\hline $60-69$ & $2.59 \pm 0.90$ & $2.58 \pm 0.87$ & $2.59 \pm 0.91$ & 0.880 \\
\hline$\geq 70$ & $2.36 \pm 0.79$ & $2.32 \pm 0.73$ & $2.38 \pm 0.82$ & 0.498 \\
\hline \multicolumn{5}{|c|}{$\mathrm{HDL}-\mathrm{C}, \mathrm{mmol} / \mathrm{L}$} \\
\hline $50-59$ & $1.07 \pm 0.26$ & $1.12 \pm 0.28$ & $1.04 \pm 0.24$ & 0.004 \\
\hline $60-69$ & $1.08 \pm 0.27$ & $1.12 \pm 0.30$ & $1.06 \pm 0.26$ & 0.007 \\
\hline$\geq 70$ & $1.09 \pm 0.25$ & $1.10 \pm 0.28$ & $1.08 \pm 0.24$ & 0.692 \\
\hline \multicolumn{5}{|c|}{ non-HDL-C, mmol/L } \\
\hline $50-59$ & $3.36 \pm 1.06$ & $3.31 \pm 1.08$ & $3.38 \pm 1.05$ & 0.539 \\
\hline $60-69$ & $3.34 \pm 1.06$ & $3.30 \pm 1.05$ & $3.35 \pm 1.07$ & 0.563 \\
\hline$\geq 70$ & $3.08 \pm 0.96$ & $2.97 \pm 0.81$ & $3.13 \pm 1.01$ & 0.128 \\
\hline \multicolumn{5}{|c|}{$\mathrm{RLP}-\mathrm{C}, \mathrm{mmol} / \mathrm{L}$} \\
\hline $50-59$ & $0.77 \pm 0.56$ & $0.71 \pm 0.54$ & $0.79 \pm 0.56$ & 0.176 \\
\hline $60-69$ & $0.75 \pm 0.46$ & $0.72 \pm 0.39$ & $0.76 \pm 0.48$ & 0.294 \\
\hline$\geq 70$ & $0.72 \pm 0.46$ & $0.65 \pm 0.31$ & $0.75 \pm 0.51$ & 0.035 \\
\hline
\end{tabular}

TC total cholesterol, TG triglyceride, LDL-C low-density lipoprotein cholesterol, $H D L-C$ high-density lipoprotein cholesterol, $R L P-C$ remnant-like particle cholesterol

0.43 vs $0.72 \pm 0.47], P=0.001$; subgroup [0.70 \pm 0.42 vs $0.76 \pm 0.51], P<0.024)$. Further, especially in the subgroup, the multivariate analysis showed that RLP-C was an independent risk factor for CAD while other traditional CAD risks might not be significantly positive.

Studies had found that RLP-C affected the formation of atherosclerosis by affecting a variety of cells [6]. The expression of low-density lipoprotein receptor-1 (LOX1) was found to be enhanced in endothelial cells at high glucose concentrations in patients with CAD and DM

Table 4 Kruskal-Wallis test between three age groups

\begin{tabular}{lllllll}
\hline \multicolumn{7}{c}{$P$ value } \\
\cline { 2 - 7 } & TC & TG & LDL-C & HDL-C & non-HDL-C & RLP-C \\
\hline 50-59 vs 60-69 & 1.000 & 1.000 & 1.000 & 0.524 & 1.000 & 0.191 \\
$\geq 70$ vs 50-59 & 0.005 & 0.007 & 0.001 & & 0.001 & \\
$\geq 70$ vs 60-69 & 0.003 & 0.009 & $<0.001$ & & 0.001 & \\
\hline
\end{tabular}

TC total cholesterol, TG triglyceride, $L D L-C$ low-density lipoprotein cholesterol, $H D L-C$ high-density lipoprotein cholesterol, RLP-C remnant-like particle cholesterol
[27]. Interestingly, RLP-C could also increase the expression of LOX-1 receptor protein by inducing the formation of superoxide associated with deoxyribonucleic acid breakage in endothelial cells, which could cause damage to endothelial cells and aggravate atherosclerosis [28]. Moreover, especially in the case of postprandial hyperlipidemia, DM and metabolic syndrome, the LOX-1 mediated RLP-C uptake mediated atherosclerosis by inducing the expression of LOX-1 [29]. At the same time, some studies had found that the level of LOX-1 was higher in obese menopausal women, which might be related to the increase of LOX-1 expression in adipose tissue [30]. We also speculated that in menopausal women with DM and CAD, RLP-C might also affect the pathogenesis of CAD by increasing the expression of LOX-1. Further research was required to determine the specific mechanism of action.

\section{Changes of RLP-C in special body conditions of menopausal women with DM and CAD}

$\mathrm{DM}$ was a risk factor for CAD, and the study of RLP-C in DM had shown that RLP-C was closely related to the internal stenosis of stent in DM patients [10]. From the perspective of gender, menopausal women with DM showed serious metabolic problems, therefore atherosclerosis was more likely to occur in this population [31]. Long-term studies had found that female patients had a lower risk of CVD at a young stage due to the protective effect of estrogen [32]. Due to the loss of estrogen protection in menopausal women with CAD and various metabolic reasons, especially the negative metabolic effects caused by DM and obesity [33, 34], the incidence of CAD in menopausal women with DM had increased significantly. Epidemiological studies had found that the mortality rate of CVD associated with early menopause was high, but the relationship between menopausal age and postmenopausal CAD was unclear [35]. Some studies had also pointed out that there was a lack of prospective studies of the relationship between acute coronary syndrome (ACS) and menopausal age in menopausal women, and the prognosis of late menopausal women after ACS was better than that of early menopausal women [36]. Therefore, we further explored the changes of RLP-C in different age groups of DM patients. Compared with other lipids, the RLP-C was not significantly different among different age groups $(P=$ 0.191), confirming that RLP-C levels were stable in menopausal women with DM, indicating consistency with increase of age.

Effect of RLP-C on the disease progression of menopausal women with DM and CAD

Clinical trials and epidemiological data supported that the effects of estrogen on the cardiovascular system were 
complex. Studies had shown that rapid, non-nuclear estrogen receptor (ER) signal transduction contributes to transcriptional regulation function of ER mediated the protective effect of estrogen [37]. In the study of the effects of hormone replacement therapy (HRT) on the progression of plasma lipoproteins and CAD in menopausal women, it was found that HRT decreased RLP-C, but increased HDL-C levels, and accelerated the progress of coronary atherosclerosis in DM women [38]. Interestingly, some studies had found that although menopausal women had higher RLP-C levels, they were not affected by HRT and were not associated with the progress of angiographic progression or clinical outcomes of CAD [39]. At the same time, studies had found that although RLP-C decreased significantly after HRT treatment, the process of coronary atherosclerosis in menopausal women also accelerated with the decline of RLP-C [40]. Among the Chinese menopausal women in our study, few patients received HRT treatment, but DM patients accounted for more than $30 \%$ of the menopausal women. At present, the relationship between DM and estrogen level was not clear, and the specific effect of HRT therapy in menopausal women with DM and CAD was worthy of further study. At the same time, we speculated that RLP-C was closely related to DM status and the special body state of menopausal women, including hormone levels and unique metabolic status.

\section{Conclusions}

Based on the results of cross-sectional studies of menopausal women, RLP-C could be an independent risk factor for menopausal women with DM and CAD.

\section{Limitations}

(a) This was a cross-sectional study and it lacked basic research as a basis, and in the clinical research of lipids, the measurement methods of VLDL-C and IDL-C were more accurate, and the calculation method of RLP-C might bring a certain degree of errors. (b) A number of cardiovascular risk factor such as lipoprotein A or apolipoprotein B were non evaluated in this study. (c) The study population lacked estrogen data and could not carry out statistical analysis of estrogen in menopausal women population. (d) The enrolled population was all female patients over 50 years old at Anzhen Hospital in 2015 , which was relatively limited in patient selection time.

\footnotetext{
Abbreviations

RLP-C: Remnant-like particle cholesterol; CAD: Coronary artery disease; DM: Diabetes mellitus; LDL-C: Low-density lipoprotein cholesterol; SBP: Systolic blood pressure; DBP: Diastolic blood pressure; BMI: Body mass index; CVD: Cardiovascular disease; TC: Total cholesterol; TG: Triglyceride; HDL-C: High-density lipoprotein cholesterol; HDL: High-density lipoprotein; LDL: Low-density lipoprotein; RLP: Remnant-like particle; VLDL-C: Very-lowdensity lipoprotein cholesterol; IDL-C: Intermediate-density lipoprotein
}

cholesterol; LOX-1: Low-density lipoprotein receptor-1; ACS: Acute coronary syndrome; ER: Estrogen receptor; HRT: Hormone replacement therapy

\section{Acknowledgements \\ We thanked all our colleagues at the department of Cardiology, Beijing Anzhen Hospital, Capital Medical University.}

\section{Authors' contributions \\ Yujie Zhou, Qianyun Guo and Xunxun Feng designed and coordinated the study. Xunxun Feng and Qianyun Guo analyzed the data and wrote the paper. Shu Zhou and Tienan Sun collected clinical data. Yuyang Liu and Zhiming Zhou revised this paper. \\ Xunxun Feng and Qianyun Guo were contributed equally to the article as the first authors. \\ All authors read and approved the final manuscript.}

\section{Funding}

This study was supported by grants from National Key Research and Development Program of China (2017YFC0908800), Beijing Municipal Administration of Hospitals' Ascent Plan (DFL20150601) and Mission plan (SML20180601), Beijing Municipal Health Commission "Project of Science and Technology Innovation Center" (PXM2020_026272_000005) to Y. Zhou. Q. Guo was supported by Chinese Scholarship Council (CSC) scholarship 201706210415 and China Postdoctoral Science Foundation 2019 M650032.

\section{Availability of data and materials}

The datasets used and/or analyzed during the current study will be available from the corresponding author on reasonable requests.

\section{Ethics approval and consent to participate}

This study was complied with the Declaration of Helsinki and approved by the Institutional Ethics Committee of Beijing Anzhen Hospital. The data retrospectively obtained from electronic medical records.

\section{Consent for publication}

Not applicable.

\section{Competing interests}

The authors declare that they have no competing interests.

Received: 5 February 2020 Accepted: 9 March 2020

Published online: 16 March 2020

References

1. Takamitsu N, Kiyotaka K. Triglycerides and remnant particles as risk factors for coronary artery disease. Curr Atheroscler Rep. 2006;8:107-10.

2. Takamitsu N, Jun-ei O, Mitsumasa $\mathrm{H}$, et al. Predictive value of remnant lipoprotein for cardiovascular events in patients with coronary artery disease after achievement of LDL-cholesterol goals. Atherosclerosis. 2011;218:163-7.

3. Joshi PH, Khokhar AA, Massaro JM, et al. Remnant lipoprotein cholesterol and incident coronary heart disease: the Jackson heart and Framingham offspring cohort studies. J Am Heart Assoc. 2016;5(5):e002765.

4. Faridi Kamil F. Quispe Renato, Martin Seth S, et al. comparing different assessments of remnant lipoprotein cholesterol: the very large database of lipids. J Clin Lipidol. 2019;13:634-44.

5. Anette V, Marianne B, Anne T-H, et al. Remnant cholesterol as a causal risk factor for ischemic heart disease. J Am Coll Cardiol. 2013;61:427-36.

6. Kawakami A, Yoshida M. Remnant lipoproteins and atherogenesis. J Atheroscler Thromb. 2005;12(2):73-6.

7. Sachiko H. Empagliflozin decreases remnant-like particle cholesterol in type 2 diabetes patients with insulin resistance. J Diabetes Investig. 2018;9:870-4.

8. Hiroshi $Y, Y u j i ~ H, ~ H i d e o ~ K$, et al. Estimation of lipoprotein profile in patients with type II diabetes and its relevance to remnant lipoprotein cholesterol levels. Atherosclerosis. 2012;222:541-4.

9. Xu X. Pandit ram Udgar, Han Le, et al. remnant lipoprotein cholesterol independently associates with in-stent restenosis after drug-eluting stenting for coronary artery disease. Angiology. 2019;70:853-9.

10. Qin Z, Zhou K, Li Y p, Wang J I, Cheng W j, Hu C p, Shi C, He H, Zhou Y j. Remnant lipoproteins play an important role of in-stent restenosis in type 2 diabetes undergoing percutaneous coronary intervention: a single-centre observational cohort study. Cardiovasc Diabetol. 2019;18:11. 
11. Elshazly MB, Mani P, Nissen S, et al. Remnant cholesterol, coronary atheroma progression and clinical events in statin-treated patients with coronary artery disease [published online ahead of print, 2019 Nov 19]. Eur J Prev Cardiol. 2019;2047487319887578.

12. Jacobson TA, Ito MK, Maki KC, et al. National lipid association recommendations for patient-centered management of dyslipidemia: part 1--full report. J Clin Lipidol. 2015;9(2):129-69.

13. Mazzone T, Chait A, Plutzky J. Addressing cardiovascular disease risk in diabetes: insights from mechanistic studies. Lancet. 2008;24(371):1800-9.

14. Mach F, Baigent C, Catapano AL, et al. 2019 ESC/EAS guidelines for the management of dyslipidaemias: lipid modification to reduce cardiovascular risk. Eur Heart J. 2020;41(1):111-88.

15. Yuki F, Takamitsu N, Takeo H, et al. Remnant lipoproteins are residual risk factor for future cardiovascular events in patients with stable coronary artery disease and on-statin low-density lipoprotein cholesterol levels $<70$ mg/dL. Circ J. 2019;83:1302-8.

16. Tani S, Yagi T, Atsumi W, Kawauchi K, Matsuo R, Hirayama A. Relation between low-density lipoprotein cholesterol/apolipoprotein $B$ ratio and triglyceride-rich lipoproteins in patients with coronary artery disease and type 2 diabetes mellitus: a cross-sectional study. Cardiovasc Diabetol. 2017; 16:123.

17. Xiaofeng $Y$, Wen $K$, Ishraq $Z M$, et al. Serum triglycerides as a risk factor for cardiovascular diseases in type 2 diabetes mellitus: a systematic review and meta-analysis of prospective studies. Cardiovasc Diabetol. 2019;18:48.

18. McNamara JR, Shah PK, Nakajima K, et al. Remnant-like particle (RLP) cholesterol is an independent cardiovascular disease risk factor in women: results from the Framingham heart study. Atherosclerosis. 2001;154:229-36.

19. Stefania L-F, Herrington David M, Reboussin David M, et al. Plasma levels of HDL subpopulations and remnant lipoproteins predict the extent of angiographically-defined coronary artery disease in postmenopausal women. Arterioscler Thromb Vasc Biol. 2008;28:575-9.

20. Mie B, Anne L, Shoaib A, et al. A third of nonfasting plasma cholesterol is in remnant lipoproteins: lipoprotein subclass profiling in 9293 individuals. Atherosclerosis. 2019;286:97-104.

21. Izumida T, Nakamura Y, Hino Y, Ishikawa S. Combined effect of small dense low-density lipoprotein cholesterol (sdLDL-C) and remnant-like particle cholesterol (RLP-C) on low-grade inflammation. J Atheroscler Thromb. 2019; 29:1-12.

22. Anette $\mathrm{V}$, Marianne $\mathrm{B}$, Anne $\mathrm{T}-\mathrm{H}$, et al. Elevated remnant cholesterol causes both low-grade inflammation and ischemic heart disease, whereas elevated low-density lipoprotein cholesterol causes ischemic heart disease without inflammation. Circulation. 2013;128:1298-309.

23. Kugiyama K, Doi H, Takazoe K, et al. Remnant lipoprotein levels in fasting serum predict coronary events in patients with coronary artery disease. Circulation. 1999;99:2858-60

24. Fukushima H, Kugiyama K, Sugiyama S, et al. Comparison of remnant-like lipoprotein particles in postmenopausal women with and without coronary artery disease and in men with coronary artery disease. Am J Cardiol. 2001; 88:1370-3.

25. Iannuzzi A, Gentile M, lannuzzo G, et al. Atherogenic lipoprotein subfractions and carotid atherosclerosis in menopausal women. Angiology. 2018;69(8):666-71.

26. Hironobu F, Seigo S, Osamu H, et al. Prognostic value of remnant-like lipoprotein particle levels in patients with coronary artery disease and type II diabetes mellitus. J Am Coll Cardiol. 2004:43:2219-24.

27. Ling L, Tatsuya S, Geneviève R. Glucose enhances endothelial LOX-1 expression: role for LOX-1 in glucose-induced human monocyte adhesion to endothelium. Diabetes. 2003;52:1843-50.

28. Kyoung SH, Ki KY, Young KK, et al. Remnant lipoprotein particles induce apoptosis in endothelial cells by NAD(P) H oxidase-mediated production of superoxide and cytokines via lectin-like oxidized low-density lipoprotein receptor-1 activation: prevention by cilostazol. Circulation. 2004;109:1022-8.

29. Yo A, Hirokazu M, Masako T, et al. Lectin-like oxidized LDL receptor-1 (LOX1) acts as a receptor for remnant-like lipoprotein particles (RLPS) and mediates RLP-induced migration of vascular smooth muscle cells. Atherosclerosis. 2008;198:272-9.

30. Brinkley Tina E, Noriaki K, Hirokazu M, et al. Elevated soluble lectin-like oxidized LDL receptor-1 (sLOX-1) levels in obese postmenopausal women. Obesity. 2008;16:1454-6.

31. Melo FM, Marado D, Palavra F, Sereno J, Coelho Á, Pinto R, Lemos ET, Teixeira F, Reis F. Diabetes abrogates sex differences and aggravates cardiometabolic risk in postmenopausal women. Cardiovasc Diabetol. 2013; 12:61.

32. Mendelsohn ME, Karas $\mathrm{RH}$. The protective effects of estrogen on the cardiovascular system. N Engl J Med. 1999:340:1801-11.

33. Christy $C$, Hugh MC, Heather $E$, et al. Changes in adiposity and other factors in relation to age at natural menopause: analyses from the coronary artery risk development (CARDIA) study. Menopause. 2019;26:162-71.

34. Anette V, Marianne B. Smith George Davey, et al. remnant cholesterol, lowdensity lipoprotein cholesterol, and blood pressure as mediators from obesity to ischemic heart disease. Circ Res. 2015;116:665-73.

35. Stefano S, Delia C, Nicoletta F, et al. Age at menopause and extent of coronary artery disease among postmenopausal women with acute coronary syndromes. Am J Med. 2016;129:1205-12.

36. Stefano S, Nuccia M, Nicoletta F, et al. Age at menopause, extent of coronary artery disease and outcome among postmenopausal women with acute coronary syndromes. Int J Cardiol. 2018;259:8-13.

37. Bernelot Moens Sophie J, Schnitzler Gavin R, Moriah N, et al. Rapid estrogen receptor signaling is essential for the protective effects of estrogen against vascular injury. Circulation. 2012;126:1993-2004.

38. Stefania L-F. Herrington David M, Horvath Katalin V, et al. effect of hormone replacement therapy on plasma lipoprotein levels and coronary atherosclerosis progression in postmenopausal women according to type 2 diabetes mellitus status. Metab Clin Exp. 2010;59:1794-800.

39. Vera B, Mark T, Judith H, et al. Remnant-like lipoproteins, hormone therapy, and angiographic and clinical outcomes: the Women's Angiographic Vitamin \& Estrogen Trial. Am Heart J. 2004;148:293-9.

40. Stefania L-F, Herrington David M, Reboussin David M, et al. Changes in remnant and high-density lipoproteins associated with hormone therapy and progression of coronary artery disease in postmenopausal women. Atherosclerosis. 2009;205:325-30.

\section{Publisher's Note}

Springer Nature remains neutral with regard to jurisdictional claims in published maps and institutional affiliations.

Ready to submit your research? Choose BMC and benefit from:

- fast, convenient online submission

- thorough peer review by experienced researchers in your field

- rapid publication on acceptance

- support for research data, including large and complex data types

- gold Open Access which fosters wider collaboration and increased citations

- maximum visibility for your research: over $100 \mathrm{M}$ website views per year

At $\mathrm{BMC}$, research is always in progress.

Learn more biomedcentral.com/submissions 